\title{
GMR
}

\section{Meta-analysis of the relationship between XRCC3 T241M polymorphism and colorectal cancer susceptibility}

\author{
L.Z. Zhang, Y.S. Li and H.Z. Liu \\ Department of General Surgery, \\ Heping Hospital Affiliated with Changzhi Medical College, Changzhi, Shanxi, China \\ Corresponding author: H.Z. Liu \\ E-mail: liuhzmed123@126.com \\ Genet. Mol. Res. 14 (4): 14831-14839 (2015) \\ Received May 11, 2015 \\ Accepted July 22, 2015 \\ Published November 18, 2015 \\ DOI http://dx.doi.org/10.4238/2015.November.18.48
}

ABSTRACT. Numerous studies have evaluated the relationship between the T241M polymorphism of the $\mathrm{X}$-ray repair cross-complementing group 3 (XRCC3) gene and colorectal cancer (CRC) risk. However, the specific relationship remains controversial. We conducted meta-analysis to investigate the relationship between the XRCC3 T241M polymorphism and CRC risk. The PubMed and Embase databases were searched for relevant studies investigating the relationship between the XRCC3 T241M polymorphism and CRC risk. The odds ratio (OR) and $95 \%$ confidence interval $(\mathrm{Cl})$ were used to assess the possible relationship. Thirteen individual case-control studies, including 4720 cases and 6104 controls, were identified and included in this meta-analysis. Meta-analyses revealed no relationship between the XRCC3 T241M polymorphism and CRC risk (TT vs MM: OR $=0.85,95 \% \mathrm{Cl}=0.63-1.14 ;$ TT vs MT: OR $=0.87,95 \% \mathrm{Cl}$ $=0.68-1.10$; dominant model: $\mathrm{OR}=1.18,95 \% \mathrm{Cl}=0.92-1.50$; recessive model: $\mathrm{OR}=0.87,95 \% \mathrm{Cl}=0.69-1.11)$. In the further subgroup analysis by ethnicity, we found no direct relationship between the polymorphism and CRC risk in either Asians or Europeans. Our findings demonstrated that 
the T241M polymorphism in the XRCC3 gene may not be a risk factor for CRC development.

Key words: Colorectal cancer; Meta-analysis; Polymorphism; XRCC3

\section{INTRODUCTION}

Colorectal cancer $(\mathrm{CRC})$ is the commonest malignancy of the gastrointestinal tract worldwide (Parkin et al., 1993). The highest morbidity of CRC occurs in Australia, Europe, and North America. In addition, the morbidity of CRC is rapidly increasing in many countries in Eastern Asia (Jemal et al., 2011). As one of the leading causes of cancer-related mortality, CRC accounts for more than 600,000 deaths every year (Ahlquist et al., 2012). Although numerous studies have been conducted, the pathogenesis of CRC is not fully understood. Epidemiological studies have shown that CRC is influenced by many environmental factors, such as lack of dietary fiber, overweight and obesity, physical inactivity, a short appendix vermiformis, a highfat diet, smoking, and excessive alcohol consumption (Cakmak et al., 2014). However, most people exposed to these environmental factors never develop CRC. Additionally, many CRC cases develop among individuals have no known risk factors, suggesting that other factors are important in the pathogenesis of CRC. Molecular biology studies have provided strong evidence that genetic factors also play important roles in colorectal carcinogenesis (Peng et al., 2014).

The X-ray repair cross-complementing group 3 (XRCC3) belongs to the RAD51 gene family, which codes for a protein that functions in the homologous recombination repair of DNA double-strand breaks, participates in DNA double-strand break/recombination repair, and likely participates in homologous recombination repair (Brenneman et al., 2000). XRCC3 is localized to human chromosomes $14 q 32.3$. T241M is the most common polymorphism of XRCC3, which substitutes a C to T at codon 241 in exon 7 (Matullo et al., 2001). Variants of the T241M polymorphism may affect the function of the encoded protein and consequently alter DNA repair capacity (Mohrenweiser et al., 2003). Therefore, the T241M polymorphism may play a role in colorectal carcinogenesis.

Previous studies have shown that the XRCC3 T241M polymorphism was associated with an increased risk of head and neck, breast, and bladder cancer (Li et al., 2011; He et al., 2012; Yin et al., 2012). In recent years, several studies have evaluated the relationship between the T241M polymorphism in the XRCC3 gene and CRC risk. However, the results of these studies are controversial, which may be related to the limitations of individual studies. Meta-analysis is a useful tool for detecting associations that may otherwise remain masked in studies of limited sample size, particularly in those evaluating rare allele frequency polymorphisms. In the present study, therefore, we performed meta-analysis to examine whether the XRCC3 T241M polymorphism is associated with $\mathrm{CRC}$ risk.

\section{MATERIAL AND METHODS}

\section{Eligibility of relevant studies}

The PubMed and Embase databases were searched (the last search was updated in 
October 1, 2014) to identify all relevant publications regarding the association between the $X R C C 3$ T241M polymorphism and CRC risk. The following search terms were used: 'Colorectal cancer/ CRC', 'X-ray repair cross-complementing group 3/XRCC3, 'T241M', and 'gene polymorphism' for relevant citations. There was no language limitation. All searched studies were retrieved, and their references were checked for other relevant publications. If sequential or multiple publications from the same data were identified, the publication reporting data from the largest or most recent study was included. Publications met the following inclusion criteria: (1) estimated the association between the XRCC3 T241M polymorphism and CRC risk, (2) used case-control designs, and (3) provided enough information to determine the frequency of alleles and genotypes in cases and controls. Major exclusion criteria were: (1) case reports, letters, reviews, meta-analysis, and editorial articles, (2) studies that were based on incomplete data and those with no usable data reported, and (3) duplicated studies.

\section{Data extraction}

Two independent investigators extracted the original data according to the inclusion criteria and exclusion criteria to ensure the accuracy of the retrieved information. The following characteristics were collected from the eligible studies: first author, year of publication, area, number of cases and controls, genotype frequencies in cases and controls, and evidence of HardyWeinberg equilibrium (HWE) in controls. For conflicting evaluations, an agreement was reached following discussion.

\section{Statistical analysis}

We assessed HWE in the controls for each study using a chi-square test, and $\mathrm{P}<$ 0.05 was considered to indicate significant disequilibrium. The pooled odds ratio (OR) with corresponding $95 \%$ confidence interval $(95 \% \mathrm{Cl})$ was calculated to assess the strength of the association between the XRCC3 T241M polymorphism and CRC risk under homozygote comparison (TT vs MM), heterozygote comparison (TT vs MT), a dominant model (MM + MT vs $\mathrm{TT})$, and a recessive model (TT + MT vs MM) between groups. Between-study heterogeneity was estimated using the $\mathrm{I}^{2}$ test. $\mathrm{I}^{2}$ ranges from $0-100 \%$ and represents the proportion of interstudy variability that can be attributed to heterogeneity rather than to chance. $I^{2}$ values of 25,50 , and $75 \%$ were defined as low, moderate, and high estimates, respectively. $\mathrm{I}^{2}>50 \%$ indicated heterogeneity across studies, and the random effects model was used for meta-analysis; otherwise, the fixed effects model was used. Subgroup analyses were performed by ethnicity and sample sizes. Sensitivity analysis was performed by removing the studies not in HWE. Funnel plot asymmetry was assessed by Begg's test to estimate potential publication bias ( $P<$ 0.05 indicated statistical significance). Meta-analysis was performed using the STATA package version 12.0 (Stata Corporation, College Station, TX, USA).

\section{RESULTS}

\section{Characteristics of retrieved studies}

By searching the databases, 73 abstracts were identified according to the search 
criteria. Base on the inclusion criteria, 13 case-control studies with full-text were included in this meta-analysis (Krupa and Blasiak, 2004; Jin et al., 2005; Moreno et al., 2006; Skjelbred et al., 2006; Yeh et al., 2007; Improta et al., 2008; Pardini et al., 2008; Curtin et al., 2009; Canbay et al., 2011; Gil et al., 2012; Zhao et al., 2012; Mucha et al., 2013; Moghtit et al., 2014). The flow chart outlining the criteria used for study selection is shown in Figure 1. The 13 casecontrol studies selected included a total of $4720 \mathrm{CRC}$ cases and 6104 healthy controls. The publication year of the included studies ranged from 2005-2014. All articles were written in English. The source of controls was mainly based on healthy populations. Among the 13 casecontrol studies, there were 8 studies of Caucasians (Krupa and Blasiak, 2004; Skjelbred et al., 2006; Improta et al., 2008; Pardini et al., 2008; Curtin et al., 2009; Canbay et al., 2011; Gil et al., 2012; Mucha et al., 2013) and 5 studies of Asians (Jin et al., 2005; Moreno et al., 2006; Yeh et al., 2007; Zhao et al., 2012; Moghtit et al., 2014). Nine studies were consistent with HWE for the genotype distribution of the controls (Moreno et al., 2006; Skjelbred et al., 2006; Yeh et al., 2007; Improta et al., 2008; Pardini et al., 2008; Curtin et al., 2009; Gil et al., 2012; Mucha et al., 2013; Moghtit et al., 2014), while 4 were not (Krupa and Blasiak, 2004; Jin et al., 2005; Canbay et al., 2011; Zhao et al., 2012). The baseline characteristics and methodological quality of all studies included are summarized in Table 1. The genotype distribution and risk allele frequency are summarized in Table 2.

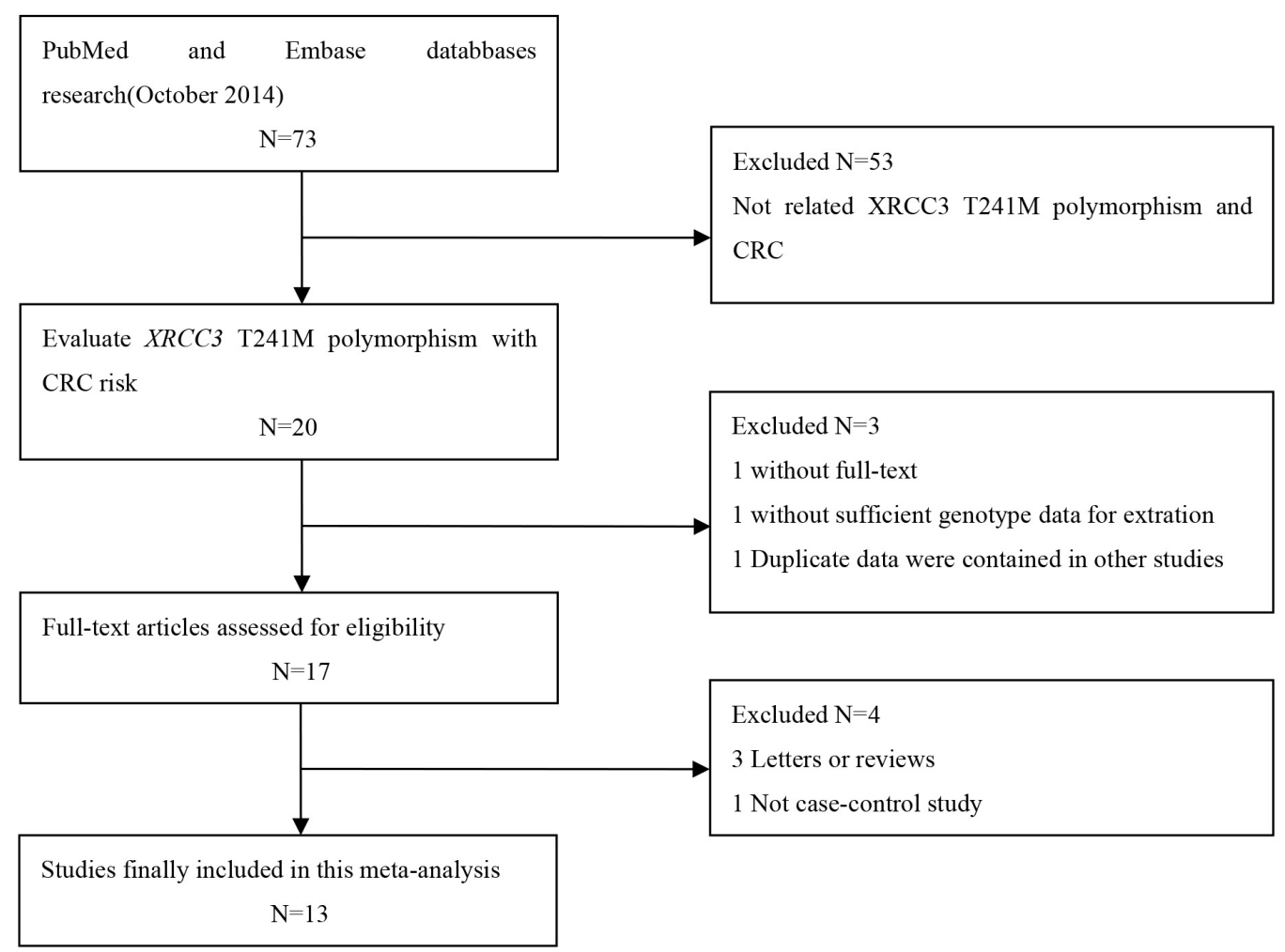

Figure 1. Detailed process of identifying eligible studies. 


\begin{tabular}{|c|c|c|c|c|c|c|c|c|c|c|c|}
\hline \multirow[t]{2}{*}{ Study included } & \multirow[t]{2}{*}{ Year } & \multirow[t]{2}{*}{ Area } & \multirow[t]{2}{*}{ Race } & \multirow[t]{2}{*}{ Cases/Controls } & \multicolumn{3}{|c|}{ Genotypes for cases } & \multicolumn{3}{|c|}{ Genotypes for controls } & \multirow[t]{2}{*}{ HWE test } \\
\hline & & & & & MM & MT & $\mathrm{TT}$ & MM & MT & $\mathrm{TT}$ & \\
\hline Jin et al. & 2005 & China & Asian & $140 / 280$ & 1 & 15 & 124 & 1 & 11 & 268 & 0.03 \\
\hline Skjelbred et al. & 2006 & Norway & Caucasian & $157 / 399$ & 20 & 73 & 64 & 60 & 201 & 138 & 0.34 \\
\hline Moreno et al. & 2006 & Spain & Asian & $361 / 316$ & 51 & 170 & 140 & 47 & 158 & 111 & 0.45 \\
\hline Yeh et al. & 2007 & China & Asian & $721 / 734$ & 1 & 60 & 660 & 2 & 74 & 658 & 0.96 \\
\hline Improta et al. & 2008 & Italy & Caucasian & $109 / 121$ & 26 & 43 & 40 & 8 & 46 & 67 & 0.98 \\
\hline Pardini et al. & 2008 & Czech & Caucasian & $532 / 532$ & 65 & 264 & 203 & 63 & 250 & 219 & 0.51 \\
\hline Curtin et al. & 2009 & USA & Caucasian & $1581 / 1948$ & 208 & 702 & 671 & 277 & 911 & 760 & 0.88 \\
\hline Canbay et al. & 2011 & Turkey & Caucasian & $79 / 247$ & 11 & 45 & 23 & 27 & 146 & 74 & 0.00 \\
\hline Krupa et al. & 2004 & Poland & Caucasian & $100 / 100$ & 9 & 55 & 36 & 3 & 47 & 50 & 0.04 \\
\hline Zhao et al. & 2012 & China & Asian & $485 / 970$ & 38 & 89 & 357 & 43 & 81 & 846 & 0.00 \\
\hline Gil et al. & 2012 & Poland & Caucasian & $132 / 100$ & 12 & 65 & 55 & 13 & 36 & 51 & 0.11 \\
\hline Mucha et al. & 2013 & Poland & Caucasian & $194 / 209$ & 25 & 72 & 97 & 25 & 104 & 80 & 0.32 \\
\hline Moghtit et al. & 2014 & Algeria & African & $129 / 148$ & 16 & 68 & 45 & 21 & 72 & 55 & 0.74 \\
\hline
\end{tabular}

Table 2. Meta-analysis results.

\begin{tabular}{|c|c|c|c|c|c|c|c|c|c|c|}
\hline \multirow[t]{2}{*}{ Subgroup } & \multirow[t]{2}{*}{ Genetic model } & \multicolumn{2}{|c|}{ Sample size } & \multirow[t]{2}{*}{$\begin{array}{l}\text { Type of } \\
\text { model }\end{array}$} & \multicolumn{2}{|c|}{$\begin{array}{c}\text { Test of } \\
\text { heterogeneity }\end{array}$} & \multicolumn{2}{|c|}{$\begin{array}{c}\text { Test of } \\
\text { association }\end{array}$} & \multicolumn{2}{|c|}{$\begin{array}{c}\text { Test of } \\
\text { publication bias }\end{array}$} \\
\hline & & Case & Control & & $\mathrm{I}^{2}$ & $P$ & $O R$ & $95 \% \mathrm{Cl}$ & $z$ & $P$ \\
\hline \multirow[t]{4}{*}{ Overall } & $T T$ vs $M M$ & 4720 & 6104 & Random & $64.8 \%$ & 0.00 & 0.85 & $0.63-1.14$ & 0.73 & 0.46 \\
\hline & $T T$ vs $M T$ & & & Random & $81.1 \%$ & 0.00 & 0.87 & $0.68-1.10$ & 0.73 & 0.46 \\
\hline & Dominant model & & & Random & $84.0 \%$ & 0.00 & 1.18 & $0.92-1.50$ & 0.73 & 0.46 \\
\hline & Recessive model & & & Random & $52.3 \%$ & 0.01 & 0.87 & $0.69-1.11$ & 0.73 & 0.46 \\
\hline \multirow[t]{4}{*}{ Asian } & $T T$ vs $M M$ & 1707 & 2300 & Random & $62.2 \%$ & 0.05 & 0.78 & $0.38-1.59$ & 1.04 & 0.30 \\
\hline & $T T$ vs $M T$ & & & Random & $91.3 \%$ & 0.00 & 0.69 & $0.35-1.35$ & 1.04 & 0.30 \\
\hline & Dominant model & & & Random & $92.0 \%$ & 0.00 & 1.42 & $0.74-2.75$ & 1.04 & 0.30 \\
\hline & Recessive model & & & Fixed & $41.3 \%$ & 0.16 & 0.79 & $0.58-1.07$ & 1.04 & 0.30 \\
\hline \multirow[t]{4}{*}{ Caucasian } & $T T$ vs $M M$ & 2884 & 3656 & Random & $69.3 \%$ & 0.00 & 0.84 & $0.58-1.23$ & 0.00 & 1.00 \\
\hline & $T T$ vs $M T$ & & & Random & $65.0 \%$ & 0.01 & 0.98 & $0.78-1.22$ & 0.00 & 1.00 \\
\hline & Dominant model & & & Random & $72.9 \%$ & 0.00 & 1.07 & $0.84-1.37$ & 0.00 & 1.00 \\
\hline & Recessive model & & & Random & $60.6 \%$ & 0.01 & 0.87 & $0.64-1.18$ & 0.00 & 1.00 \\
\hline Sample size & $T T$ vs $M M$ & 3837 & 4899 & Random & $65.8 \%$ & 0.01 & 0.97 & $0.70-1.34$ & 0.00 & 1.00 \\
\hline \multirow[t]{3}{*}{$>500$} & $T T$ vs $M T$ & & & Random & $87.9 \%$ & 0.00 & 0.94 & $0.68-1.31$ & 0.00 & 1.00 \\
\hline & Dominant model & & & Random & $89.8 \%$ & 0.00 & 1.05 & $0.75-1.46$ & 0.00 & 1.00 \\
\hline & Recessive model & & & Fixed & $42.6 \%$ & 0.12 & 1.01 & $0.87-1.16$ & 0.00 & 1.00 \\
\hline Consistent & $T T$ vs $M M$ & 3916 & 4507 & Random & $55.9 \%$ & 0.02 & 1.00 & $0.75-1.33$ & 0.34 & 0.73 \\
\hline \multirow{3}{*}{ with HWE } & $T T$ vs $M T$ & & & Random & $55.3 \%$ & 0.02 & 1.06 & $0.89-1.26$ & 0.34 & 0.73 \\
\hline & Dominant model & & & Random & $64.1 \%$ & 0.00 & 0.97 & $0.80-1.16$ & 0.34 & 0.73 \\
\hline & Recessive model & & & Fixed & $45.4 \%$ & 0.07 & 1.03 & $0.89-1.18$ & 0.34 & 0.73 \\
\hline
\end{tabular}

\section{Meta-analysis results}

A summary of the meta-analysis findings regarding the association between the XRCC3 T241M polymorphism and CRC risk is shown in Table 2 and Figures 2 and 3. Overall, we found no significant association between the XRCC3 T241M polymorphism and CRC in the total analysis (TT vs MM: OR $=0.85,95 \% \mathrm{Cl}=0.63-1.14 ;$ TT vs $\mathrm{MT}$ : OR $=0.87,95 \% \mathrm{Cl}=0.68$ 1.10; dominant model: $\mathrm{OR}=1.18,95 \% \mathrm{Cl}=0.92-1.50$; recessive model: $\mathrm{OR}=0.87,95 \% \mathrm{Cl}=$ 0.69-1.11).

\section{Subgroup analysis}

When stratified according to ethnicity, we detected no significant association in Asians 
(TT vs $\mathrm{MM}: \mathrm{OR}=0.78,95 \% \mathrm{Cl}=0.38-1.59 ;$ TT vs $\mathrm{MT}$ : OR $=0.69,95 \% \mathrm{Cl}=0.35-1.35$; dominant model: $\mathrm{OR}=1.42,95 \% \mathrm{Cl}=0.74-2.75$; recessive model: $\mathrm{OR}=0.79,95 \% \mathrm{Cl}=0.58-1.07$ ) and in Caucasians (TT vs MM: OR =0.84, 95\%Cl =0.58-1.23; TT vs MT: OR =0.98, 95\%Cl = 0.78-1.22; dominant model: $\mathrm{OR}=1.07,95 \% \mathrm{Cl}=0.84-1.37$; recessive model: $\mathrm{OR}=0.87,95 \% \mathrm{Cl}=0.64-$ 1.18). In stratified analysis by sample size (subjects $>500$ ), we detected no significant association between the T241M polymorphism and CRC (TT vs MM: OR $=0.97,95 \% \mathrm{Cl}=0.70-1.34$; TT vs MT: $\mathrm{OR}=0.94,95 \% \mathrm{Cl}=0.68-1.31$; dominant model: $\mathrm{OR}=1.05,95 \% \mathrm{Cl}=0.75-1.46$; recessive model: $\mathrm{OR}=1.01,95 \% \mathrm{Cl}=0.87-1.16)$.

Study
ID

Figure 2. Association between the XRCC3 T241M polymorphism and CRC risk (TT vs MM): total analysis.

\section{Sensitivity analysis and publication bias}

Sensitivity analysis was performed by omission of non-HWE studies and the results were not altered, indicating that the results of this meta-analysis were statistically significant (Table 2). Publication bias of the literature was assessed by Begg's funnel plot (Figure 4 and Table 2). The funnel plot was used to measure the asymmetry of the funnel plot. The results of the Begg's funnel plot test are shown in Table 2. The results revealed no publication bias (all P > 0.05). 


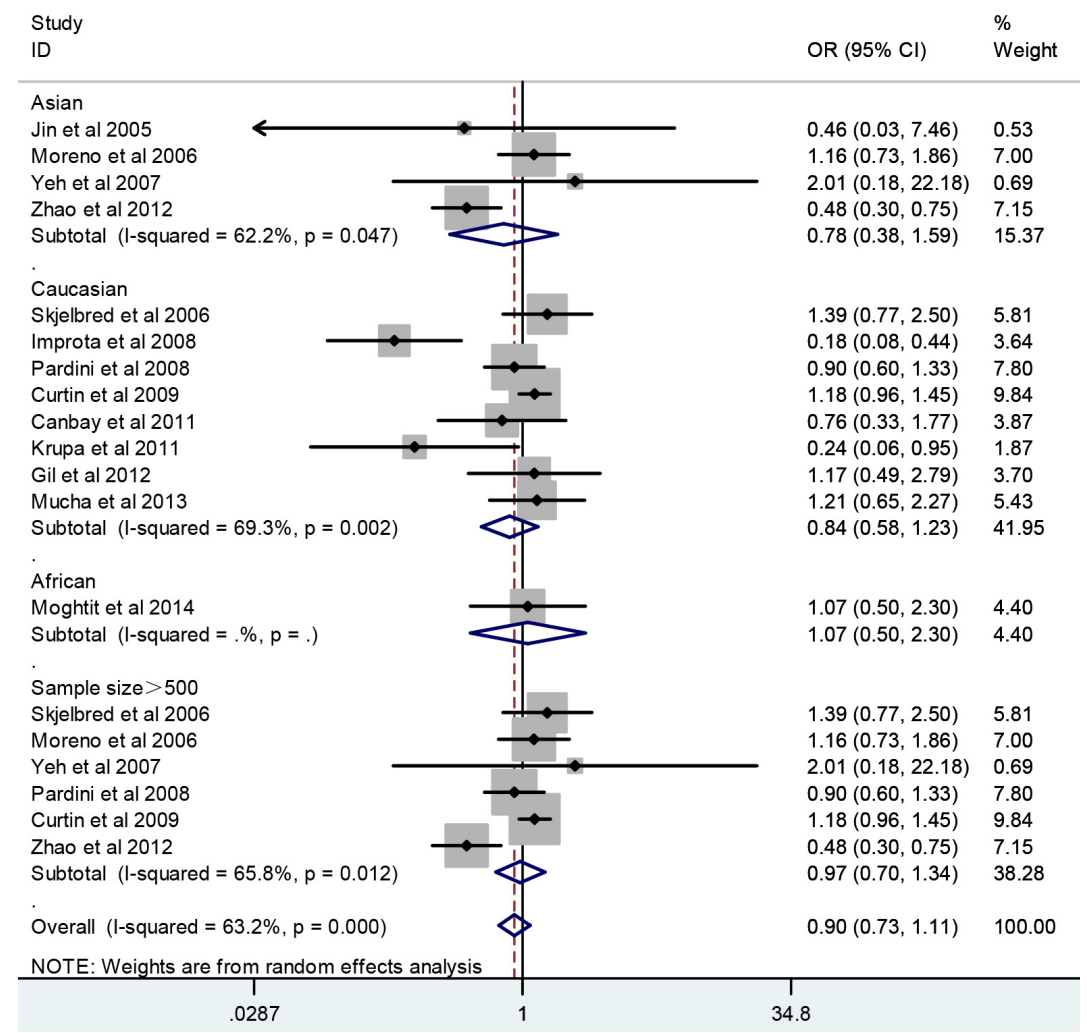

Figure 3. Association between the XRCC3 T241M polymorphism and CRC risk (TT vs MM): subgroup analysis by ethnicity and sample sizes $>500$.

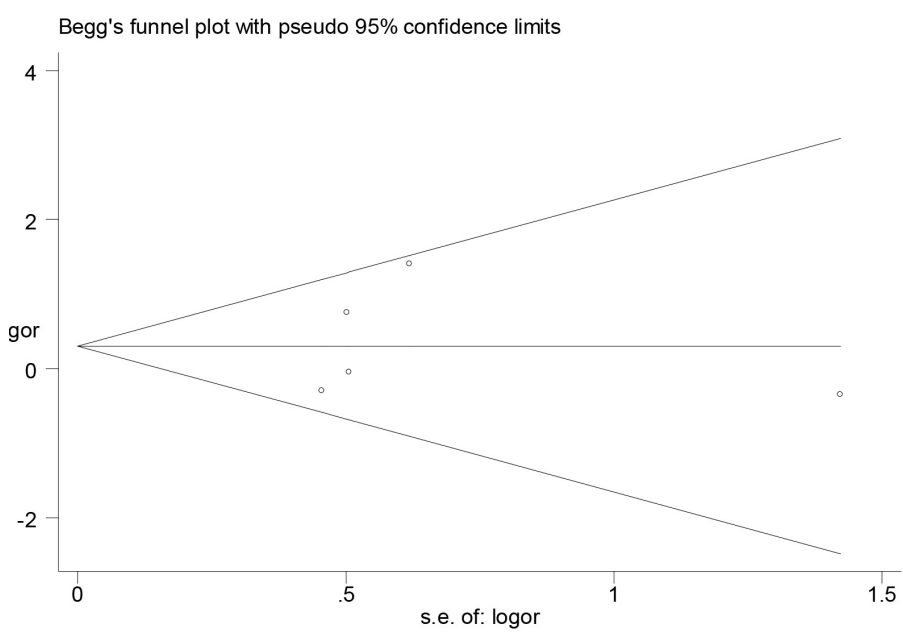

Figure 4. Publication bias for the association between the XRCC3 T241M polymorphism and CRC risk (TT vs MM). 


\section{DISCUSSION}

CRC is a multifactorial disease with a pathogenesis that is not fully understood. Accumulated evidence has indicated that CRC is determined by a complex interaction between environmental and genetic factors. The DNA repair system is important for maintaining the stability of the normal genomic function of cells. XRCC3 is the major gene involved in the restoration phase of DNA damage. Recently, numerous studies have examined the association between the XRCC3 T241M polymorphism and CRC. However, the results are inconsistent, likely because these studies were single case-control studies including small sample sizes (Moghtit et al., 2014). To clarify these inconsistent findings, we conducted this meta-analysis to obtain more reliable results by combining a larger number eligible studies, increasing the sample size, and conducting subgroup analysis.

The current meta-analysis, which included 4720 patients and 6104 controls, explored the association between the XRCC3 T241M polymorphism and CRC risk. The results of the present meta-analysis revealed that the XRCC3 T241M polymorphism is not associated with an increased or decreased risk of CRC. Furthermore, we performed ethnicity-specific subgroup analysis. Subgroup analysis results showed that the XRCC3 T241M polymorphism was not associated with $\mathrm{CRC}$ risk both in Asians and in Caucasians. There was only one study of Africans, and thus further studies examining Africans should be conducted (Moghtit et al., 2014). Stratification by sample size (> 500) for subgroup analysis revealed no significant association, indicating there was no smallstudy bias in our meta-analysis. Deviation of allelic distributions from HWE may have contributed to between-study heterogeneity. Sensitivity analysis conducted by limiting this meta-analysis to those studies that were consistent with HWE revealed our results were reliable. There was no evidence of publication bias in this meta-analysis (all $\mathrm{P}>0.05$ ).

The results of the present meta-analysis revealed that the XRCC3 T241M polymorphism is not associated with the risk of CRC. The function of the XRCC3 T241M polymorphism with CRC may be affected by gene-gene and gene-environment interactions. A previous study showed that the XRCC1 Arg399GIn and XRCC3 T241M polymorphisms synergistically increased the risk of CRC (Zhao et al., 2012). However, in contrast to many genetic polymorphisms, the XRCC3 T241M polymorphism was not associated with environmental factors such as alcohol drinking and cigarette smoking (Goode et al., 2002; Skjelbred et al., 2006). Further studies of gene-gene and gene-environment interaction should be conducted.

There were several limitations to this meta-analysis. First, because of incomplete raw data, some relevant studies could not be included in our analysis. Second, our results were based on unadjusted estimates, and a more precise analysis should be conducted if raw data from each individual study were available. This would allow for adjustment by other co-variants, including age, gender, environmental factors, and other lifestyle factors. Third, we only included articles written in English, which may have eliminated other articles.

In conclusion, the T241M polymorphism in the XRCC3 gene may not contribute to the risk of CRC. Further studies should be performed to validate these results.

\section{Conflicts of interest}

The authors declare no conflict of interest. 


\section{REFERENCES}

Ahlquist DA, Zou H, Domanico M, Mahoney DW, et al. (2012). Next-generation stool DNA test accurately detects colorectal cancer and large adenomas. Gastroenterology 142: 248-256.

Brenneman MA, Weiss AE, Nickoloff JA and Chen DJ (2000). XRCC3 is required for efficient repair of chromosome breaks by homologous recombination. Mutat. Res. 459: 89-97.

Cakmak YO, Ergelen R, Ekinci G and Kaspar EC (2014). The short appendix vermiformis as a risk factor for colorectal cancer. Clin. Anat. 27: 498-502.

Canbay E, Cakmakoglu B, Zeybek U, Sozen S, et al. (2011). Association of APE1 and hOGG1 polymorphisms with colorectal cancer risk in a Turkish population. Curr. Med. Res. Opin. 27: 1295-1302.

Curtin K, Samowitz WS, Wolff RK, Ulrich CM, et al. (2009). Assessing tumor mutations to gain insight into base excision repair sequence polymorphisms and smoking in colon cancer. Cancer Epidemiol. Biomarkers Prev. 18: 3384-3388.

Gil J, Ramsey D, Stembalska A, Karpinski P, et al. (2012). The C/A polymorphism in intron 11 of the XPC gene plays a crucial role in the modulation of an individual's susceptibility to sporadic colorectal cancer. Mol. Biol. Rep. 39: 527-534.

Goode EL, Ulrich CM and Potter JD (2002). Polymorphisms in DNA repair genes and associations with cancer risk. Cancer Epidemiol. Biomarkers Prev. 11: 1513-1530.

He XF, Wei W, Su J, Yang ZX, et al. (2012). Association between the XRCC3 polymorphisms and breast cancer risk: metaanalysis based on case-control studies. Mol. Biol. Rep. 39: 5125-5134.

Improta G, Sgambato A, Bianchino G, Zupa A, et al. (2008). Polymorphisms of the DNA repair genes XRCC1 and XRCC3 and risk of lung and colorectal cancer: a case-control study in a Southern Italian population. Anticancer Res. 28: 2941-2946.

Jemal A, Bray F, Center MM, Ferlay J, et al. (2011). Global cancer statistics. CA Cancer J. Clin. 61: 69-90.

Jin MJ, Chen K, Song L, Fan CH, et al. (2005). The association of the DNA repair gene XRCC3 Thr241Met polymorphism with susceptibility to colorectal cancer in a Chinese population. Cancer Genet. Cytogenet. 163: 38-43.

Krupa R and Blasiak J (2004). An association of polymorphism of DNA repair genes XRCC1 and XRCC3 with colorectal cancer. J. Exp. Clin. Cancer Res. 23: 285-294.

Li F, Li C, Jiang Z and Gao X (2011). XRCC3 T241M polymorphism and bladder cancer risk: a meta-analysis. Urology 77: 511. e1-5.

Matullo G, Guarrera S, Carturan S, Peluso M, et al. (2001). DNA repair gene polymorphisms, bulky DNA adducts in white blood cells and bladder cancer in a case-control study. Int. J. Cancer 92: 562-567.

Moghtit FZ, Aberkane MS, Le Morvan V, Louhibi L, et al. (2014). No association between XRCC3 Thr241Met and XPD Lys $751 \mathrm{GIn}$ polymorphisms and the risk of colorectal cancer in West Algerian population: a case-control study. Med. Oncol. 31: 942.

Mohrenweiser HW, Wilson DM 3rd and Jones IM (2003). Challenges and complexities in estimating both the functional impact and the disease risk associated with the extensive genetic variation in human DNA repair genes. Mutat. Res. 526: 93-125.

Moreno V, Gemignani F, Landi S, Gioia-Patricola L, et al. (2006). Polymorphisms in genes of nucleotide and base excision repair: risk and prognosis of colorectal cancer. Clin. Cancer Res. 12: 2101-2108.

Mucha B, Przybylowska-Sygut K, Dziki AJ, Dziki L, et al. (2013). Association of Thr241Met polymorphism of XRCC3 gene with risk of colorectal cancer in the Polish population. Pol. J. Pathol. 64: 185-190.

Pardini B, Naccarati A, Novotny J, Smerhovsky Z, et al. (2008). DNA repair genetic polymorphisms and risk of colorectal cancer in the Czech Republic. Mutat. Res. 638: 146-153.

Parkin DM, Pisani P and Ferlay J (1993). Estimates of the worldwide incidence of eighteen major cancers in 1985. Int. J. Cancer 54: 594-606.

Peng Q, Lao X, Tang W, Chen Z, et al. (2014). CASP8 -652 6N del polymorphism contributes to colorectal cancer susceptibility: evidence from a meta-analysis. PLOS ONE 9: e87925.

Skjelbred CF, Saebø M, Wallin H, Nexø BA, et al. (2006). Polymorphisms of the XRCC1, XRCC3 and XPD genes and risk of colorectal adenoma and carcinoma, in a Norwegian cohort: a case control study. BMC Cancer 6: 67.

Yeh CC, Sung FC, Tang R, Chang-Chieh CR, et al. (2007). Association between polymorphisms of biotransformation and DNArepair genes and risk of colorectal cancer in Taiwan. J. Biomed. Sci. 14: 183-193.

Yin QH, Liu C, Li L, Zu XY, et al. (2012). Association between the XRCC3 T241M polymorphism and head and neck cancer susceptibility: a meta-analysis of case-control studies. Asian Pac. J. Cancer Prev. 13: 5201-5205.

Zhao Y, Deng X, Wang Z, Wang Q, et al. (2012). Genetic polymorphisms of DNA repair genes XRCC1 and XRCC3 and risk of colorectal cancer in Chinese population. Asian Pac. J. Cancer Prev. 13: 665-669. 